\title{
BMP4/Smad1 Signalling Promotes Spinal Dorsal Column Axon Regeneration and Functional Recovery After Injury
}

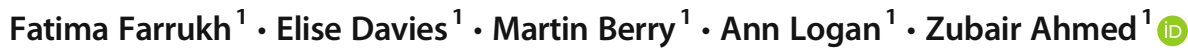

Received: 4 January 2019 / Accepted: 13 March 2019 / Published online: 28 March 2019

(C) The Author(s) 2019

\begin{abstract}
Signalling through the BMP4/Smad1 pathway promotes corticospinal tract axon regeneration and functional recovery in mice. However, unlike humans and rats, mice do not cavitate. Here, we investigated if activation of the BMP4/Smad1 pathway promotes axon regeneration and functional recovery in a rat model that cavitates. We show that dorsal root ganglion neurons (DRGN) in injury models, including the non-regenerating dorsal column (DC) and the regenerating sciatic nerve (SN) crush and preconditioning (p) $\mathrm{SN}+\mathrm{DC}(\mathrm{pSN}+\mathrm{DC})$ paradigms, regulate the BMP4/Smad1 signalling pathway. For example, mRNA expression of positive regulators of the BMP4/Smad1 pathway was highly up-regulated whilst negative regulators were significantly down-regulated in DRGN in the regenerating $\mathrm{SN}$ and $\mathrm{pSN}+\mathrm{DC}$ models compared to non-regenerating DC models, matched by concomitant changes in protein expression detected in DRGN by immunohistochemistry. BMP4 peptide promoted significant DRGN survival and disinhibited neurite outgrowth in vitro, whilst AAV-BMP4 delivery in vivo stimulated DC axon regeneration and functional recovery in a model that cavitates. Our results show that activation of the BMP4/Smad1 pathway is a potential therapeutic target in the search for axon regenerative signalling pathways in the CNS.
\end{abstract}

Keywords Spinal cord injury $\cdot$ BMP4 $\cdot$ Smad $1 \cdot$ Dorsal root ganglion neurons $\cdot$ Dorsal column $\cdot$ Axon regeneration

\section{Introduction}

Several signalling pathways have been associated with axon regeneration after spinal cord injury (SCI). These include the phophoinositide-3-kinase (PI3K) and extracellular receptor kinase (ERK) pathways that are essential for axon assembly and neurotrophin-induced axonal branching [1-3]. The PI3KAkt pathway also regulates local protein synthesis via the mammalian target of rapamycin (mTOR) signalling pathway with adult neurons requiring mTOR signalling to promote axon regeneration [4]. It is not known if mTOR signalling plays a role in the regeneration of ascending long-tract dorsal root ganglion neuron (DRGN) dorsal column (DC) projections, but an mTOR independent pathway is implicated, since pSN also promotes DC axon regeneration $[5,6]$. The genes of many PI3K independent axogenic signalling proteins are

Zubair Ahmed

z.ahmed.1@bham.ac.uk

1 Neuroscience and Ophthalmology, Institute of Inflammation and Ageing, College of Medical and Dental Sciences, University of Birmingham, Birmingham B15 2TT, UK transcribed in axotomised DRGN [7-9]. Prominent among the latter is the bone morphogenetic protein 4 (BMP4)/ mothers against decapentaplegic homologue 1 (Smad1) pathway. Smad1 activation, nuclear accumulation and gene transcription require BMP receptor (BMPR) binding and histone 4 (H4) acetylation [10] when BMP/Smad and PI3K/Akt pathways interact to effect axogenesis. For example, (1) PI3K/Akt induces nuclear localisation of BMP4-activated Smad1 and regulates Smad induction of axon regeneration-related transcription factors and (2) BMP4 activates Akt by suppression of PTEN, stimulation of MAPK and autocrine induction of growth factor secretion $[11,12]$.

BMP4/Smad1 signalling stimulates peripheral DRGN axon growth developmentally, and down-regulation of the pathway with age correlates with a decline in axon growth potential [13]. SN axotomy up-regulates Smad1 [10] and BMP2/4 injected into DRG potentiates SN growth [14]. DRGN neurite outgrowth is suppressed after knockdown of the BMP coreceptor (repulsive guidance molecule b-RGMb), and conversely, inhibition of the BMPR antagonist Noggin in mature DRGN in vivo potentiates $\mathrm{SN}$ axon regeneration [15]. The inactivation of Smad1 in DRGN after DC lesions correlates with failed axon regeneration, whereas DRG injection of 
BMP4 activates Smad1 and promotes DC axon regeneration in the lesioned adult mouse cord [13].

However, the mouse cord does not cavitate after SCI whereas the rat cord does [16], and hence, the impact of BMP4/Smad1 activation in a model that cavitates as in humans remains to be investigated. Here, we used the rat model, which cavitates, to determine the contribution of the BMP4/Smad1 signalling pathway on DC axon regeneration and return of locomotor and sensory function. We show that BMP4/Smad1 is activated when DRGN axons regenerate after an $\mathrm{SN}$ and $\mathrm{pSN}+\mathrm{DC}$ lesions, BMP4 peptide promotes disinhibited DRGN neurite outgrowth in the presence of inhibitory CNS myelin extracts (CME), whilst BMP4 overexpression in DRGN in vivo enhances DC axon regeneration and promotes functional recovery in adult rats, despite the presence of spinal cord cavities. These results suggest that the BMP4/Smad1 pathway is a potential target for therapeutic intervention in SCI patients.

\section{Methods}

\section{Animals}

Adult (6-8-week old) female Sprague-Dawley rats (180$250 \mathrm{~g}$ ) (Charles River, Margate, UK) were used. Animals were maintained in the animal facility of University of Birmingham, UK, under standard conditions $\left(21{ }^{\circ} \mathrm{C}, 12-\mathrm{h}\right.$ light-dark cycle) with free access to food and water. All surgery was performed in strict accordance to the guidelines of both the UK Animals Scientific Procedures Act, 1986 and the Revised European Directive 1010/63/EU. Experiments were licenced by the UK Home Office and ethically approved by the University of Birmingham's animal welfare and ethical review board. Experiments also conformed to the recommendations of the use of animals by the Federation of the European Laboratory Animal Science Associations.

\section{Experimental Design}

For in vivo microarray experiments, four adult female Sprague-Dawley rats/group ( $n=12$ rats/group (3 independent repeats)) were randomly assigned to (1) uninjured intact controls (IC), (2) sham-treated controls (sham: partial laminectomy but no DC crush injury), (3) non-regenerating DC model (DC) that received a DC lesion alone, (4) regenerating $\mathrm{SN}$ model ( $\mathrm{SN}$ ) that received a $\mathrm{SN}$ lesion alone, and $(5)$ regenerating pre-conditioning $\mathrm{SN}$ lesion $(\mathrm{pSN})+\mathrm{DC}$ injury model (pSN + DC-pSN lesion performed 7 days before the DC lesion). Tissues were harvested at 10 days after DC, $\mathrm{SN}$ and pSN + DC lesions for the microarray, qRT-PCR and immunohistochemistry studies (Fig. 1a) and at 6 weeks after DC lesion for the in vivo adeno-associated virus 8 (AAV8;
AAV serotype 8) delivered BMP4 (AAV-BMP4) studies (Fig. 1b). AAV8 has previously been shown by others and ourselves to preferentially transduce large-diameter neurons that form the ascending tracts of the DC [17]. All in vivo experiments, except the microarray study, contained six rats/group, repeated on three independent occasions (total $n=18$ rats/group/test) and performed by an investigator masked to the treatment conditions. Ten days after DC lesion was chosen since Q-PCR and immunohistochemistry studies at 1, 3, 5, 7, 10 and 17 days after DC lesion showed the greatest gene/ protein changes between groups (not shown).

To test the potential of AAV-BMP4 to disinhibit DC axon regeneration and enhance functional recovery in vivo, groups of six adult female Sprague-Dawley were randomly assigned to treatment groups. At 1 week before DC injury (week 1), groups of animals received intra-DRG injection of either control AAV8-Null (Vector Biolabs, Malvern, PA, USA; AAV serotype 8 with a $\mathrm{CMV}$ promoter but no transgene) $(\mathrm{DC}+$ AAV-Null) or AAV-BMP4 (DC + AAV-BMP4) (Fig. 1b). After 7 days, a group of animals was designated as shamtreated control (sham). Animals from each group received either a sham (partial laminectomy and exposure of the spinal cord but no DC lesion) or DC injury (partial laminectomy followed by crush injury of the DC tracts) [16] 7 days later. Animals were allowed to survive for 6 weeks during which behavioural tests were performed by individuals masked to the treatment conditions at baseline, 2 days and then weekly at 1-6 weeks after injury [18, 19]. Electrophysiology was performed at 6 weeks after injury before harvesting tissues for immunohistochemistry (Fig. 1b) [19]. All in vivo experiments were repeated on three independent occasions (total $n=$ $18 \mathrm{rats} /$ group/treatment).

\section{Surgery and Tissue Harvesting}

All animals were injected with Buprenorphine to provide analgesia before anaesthesia using 5\% isoflurane with $1.8 \mathrm{l} / \mathrm{min}$ $\mathrm{O}_{2}$. After a partial laminectomy, DC were crushed bilaterally at the level of T8 using calibrated watchmaker's forceps [16, 20, 21]. The tips of the forceps, separated to a width of $1 \mathrm{~mm}$, were inserted into the cord through the dorsal meninges to a depth of $1 \mathrm{~mm}$ and the DC crushed by tip approximation. The left SN was exposed at mid-thigh level and crushed using fine forceps at the level of the sacrotuberous ligament. In the $\mathrm{pSN}+\mathrm{DC}$ model, SN were crushed 1 week before DC crush injury. Rats were housed under standard conditions after surgery along with their cage mates in groups of four rats. For the microarray and immunohistochemistry studies, rats were killed at 10 days after DC lesion by $\mathrm{CO}_{2}$ exposure when L4/ L5 DRG was harvested from the ipsilateral (treated) and contralateral (untreated) sides. DRG were snap frozen in liquid $\mathrm{N}_{2}$ before RNA extraction, and for immunohistochemistry, animals were intracardially perfused with $4 \%$ formaldehyde in 
Fig. 1 Experimental design of a in vivo microarray and immunohistochemistry studies and $\mathbf{b}$ the in vivo AAV-BMP4 study

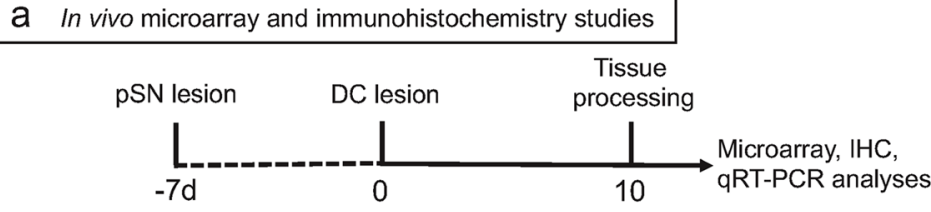

\begin{tabular}{|c|c|c|}
\hline Treatment & $\mathrm{n}(\mathrm{DRG})$ & Measured endpoints \\
\hline Sham & $\begin{array}{c}12 \text { (6 rats) (microarray) } \\
18 \text { (9 rats) (IHC and } \\
\text { qRT-PCR) }\end{array}$ & Gene expression and protein localisation \\
\hline DC & $\begin{array}{c}12 \text { (6 rats) (microarray) } \\
18 \text { (9 rats) (IHC and } \\
\text { qRT-PCR) }\end{array}$ & Gene expression and protein localisation \\
\hline SN & $\begin{array}{c}12 \text { (6 rats) (microarray) } \\
18 \text { (9 rats) (IHC and } \\
\text { qRT-PCR) }\end{array}$ & Gene expression and protein localisation \\
\hline $\mathrm{pSN}+\mathrm{DC}$ & $\begin{array}{c}12 \text { (6 rats) (microarray) } \\
18 \text { (9 rats) (IHC and } \\
\text { qRT-PCR) }\end{array}$ & Gene expression and protein localisation \\
\hline
\end{tabular}

b In vivo AAV-BMP4 studies

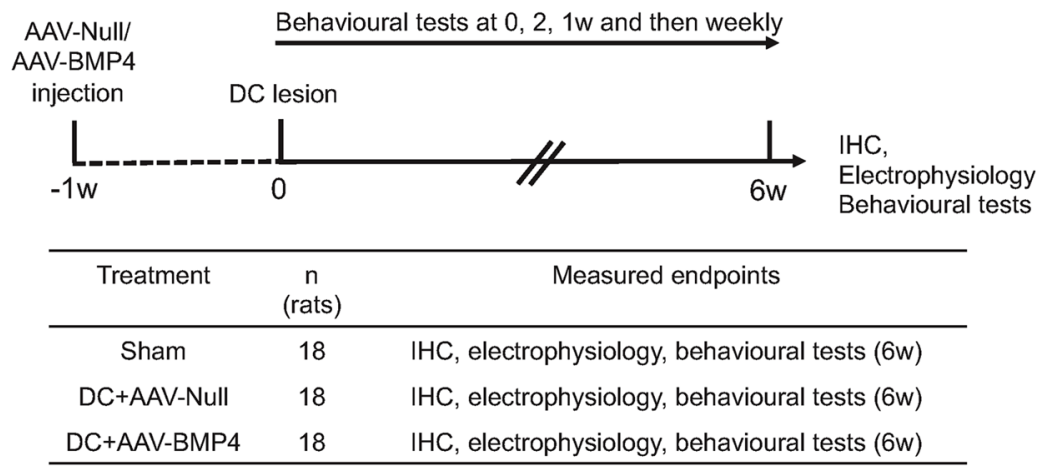

phosphate-buffered saline (PBS) and both ipsilateral and contralateral L4/L5 DRG processed as described below.

\section{Intra-DRG Injections}

The left L4/5 DRG were exposed and injected as described by us previously [17] with either $10^{13}$ viral genomes of AAV-Null (control; Vector Biolabs) or AAV-BMP4 (gift from Hongyang Zou, Mount Sinai School of Medicine, New York, USA) in a total volume of 5- $\mu$ l sterile PBS using a glass micropipette.

\section{Microarray Analysis}

RNA was extracted from a total of $12 \mathrm{DRG} /$ treatment $(n=4$ $\mathrm{DRG} /$ treatment, 3 independent repeats) harvested at 10 days after DC lesion from each experimental group detailed above using the RNeasy kit (Qiagen Ltd., Crawley, UK) according to the manufacturer's instructions. The rat genome AROSTM V3.0 set (Operon Biotechnologies GmbH, Cologne, Germany) containing 29,962 long-mer probes representing 22,012 genes and 27,044 gene transcripts was used for the microarray analysis (Read et al., 2009). Briefly, either Cy3or Cy5-labelled oligonucleotide probes were hybridised and slides were scanned with an Axon GenePix 4000B scanner (Molecular Devices Ltd., Berkshire, UK); background fluorescence values for $\mathrm{Cy} 3$ and $\mathrm{Cy} 5$ channels were subtracted and data analysed using GeneSpring GX7 (Agilent, Berkshire, UK) normalised by the Lowess method. Data were filtered below the $P<0.05$ threshold, and fold changes $>2$ above sham control levels were taken as significant. Each condition was replicated $\times 4$ in duplicate.

\section{Quantitative Real-Time PCR}

RNA was extracted from $n=6 \mathrm{DRG} /$ treatment, which were pooled together at 10 days after DC lesion, using the RNeasy kit (Qiagen Ltd., Crawley, UK) according to the manufacturer's instructions. Experiments were repeated on three independent occasions with total $n=18 \mathrm{DRG} /$ treatment. Selected genes of the BMP4/Smad1 pathway were validated by Q-PCR using pre-validated primer sequences (Table 1) from complementary DNA prepared from 
Table 1 List of primers used for the BMP4/Smad1 pathway

\begin{tabular}{|c|c|c|}
\hline Gene & Primer sequence & Ref \\
\hline smadl & $\begin{array}{l}\text { Forward: 5'-ACCTGCTTACCTGCCTCCTG-3' } \\
\text { Reverse: 5'-CATAAGCAACCGCCTGAACA-3' }\end{array}$ & Kuo et al., 2011 \\
\hline $\operatorname{smad5}$ & $\begin{array}{l}\text { Forward: 5'-CTGGGATTACAGGACTTGACC-3' } \\
\text { Reverse: 5'-AAGTTCCAATTAAAAAGGGAGGA-3' }\end{array}$ & Kuo et al., 2011 \\
\hline $\operatorname{smad8}$ & $\begin{array}{l}\text { Forward: 5'-GTATCATCGCCAGGATGTCA-3' } \\
\text { Reverse: 5'- TGTGGGGAGCCCATCTGAGT-3' }\end{array}$ & Yew et al., 2005 \\
\hline bmp-4 & $\begin{array}{l}\text { Forward: 5' GGCAGAGGAGGAGGGAGGGAGGGAAGGAGC-3' } \\
\text { Reverse: 5'-CAGTAGCGGGCTCGCCAGCAGCAGCTCCTG-3' }\end{array}$ & Kawai and Sugiura, 2001 \\
\hline$c r e b-p$ & $\begin{array}{l}\text { Forward: 5'-AAGCTGAAAGTCAACAAATGACAGTT-3' } \\
\text { Reverse: 5'-TGGACTGTCTGCCCATTGG-3' }\end{array}$ & Shankar et al., 2005 \\
\hline$m k k 3 / 6$ & $\begin{array}{l}\text { Forward: 5'-GGCCCCTGAAAGAATAAACCC-3' } \\
\text { Reverse: 5'-CGAAGGATGGCCAACTCAATC-3' }\end{array}$ & Galan-Moya et al., 2011 \\
\hline gapdh & $\begin{array}{l}\text { Forward: 5'-ACCACAGTCCATGCCATCAC-3' } \\
\text { Reverse: 5'-TCCACCACCCTGTTGCTGTA-3' }\end{array}$ & Xu et al., 2010 \\
\hline
\end{tabular}

extracted mRNA, and Q-PCR was performed using LightCycler Q-PCR machine (Roche, Burgess Hill, UK) following previously published methods [22]. Fold changes were computed using the $\Delta \Delta \mathrm{Ct}$ method and the mean \pm SEM is presented from the three independent repeats.

\section{Immunohistochemistry of DRG}

Ipsilateral and contralateral L4/L5 DRG ( $n=6 \mathrm{DRG} /$ treatment, 3 independent repeats; total $n=18 \mathrm{DRG} /$ treatment) from perfusion-fixed rats were cryoprotected through a graded series of sucrose solutions and blocked in optimal cutting temperature (OCT) compound (TAAB Laboratories, Peterborough, UK). DRG cryosections were adhered onto charged glass slides and sections from the middle of each DRG were chosen for immunohistochemistry. After washing in PBS, non-specific antibody binding was blocked with $3 \%$ bovine serum albumin diluted in PBS containing $0.1 \%$ Triton-X100 before overnight incubation at $4{ }^{\circ} \mathrm{C}$ with the relevant primary antibodies (Table 2). Regenerating axons in the DC were detected using GAP-43 immunohistochemistry since Cholera toxin B labelling in our hands did not label regenerating axons by retrograde transport labelling in the rat [23], despite others demonstrating successful labelling [6, 24]. Sections not exposed to primary antibody were included as negative controls in each run, washed in PBS, incubated with relevant secondary antibodies conjugated to either Alexa488 or Alexa594 for $1 \mathrm{~h}$ at room temperature (RT; Table 2), washed in several changes of PBS and mounted using Vectashield containing DAPI (Vector Laboratories, Peterborough, UK). Sections were examined using a Zeiss epi-fluorescent microscope attached to an Axiocam HRc run by Axiovision software (all from Zeiss, Hertfordshire, UK). Negative controls were used to set the background threshold level for each antibody before image capture.

\section{Primary DRGN Cultures}

Primary adult rat (Sprague-Dawley rats, 170-220 g, Charles River) DRGN were prepared from intact DRG according to our previously published methods [25]. DRG cells from ipsilateral and contralateral L4-7 DRG pairs were dissociated using $0.025 \%$ collagenase (Sigma, Poole, UK) and plated (500/well) in supplemented neurobasal-A (NBA; containing B-27 supplement and L-glutamine; all from Invitrogen, Paisley, UK), plated in 8-well chamber slides pre-coated with $100 \mu \mathrm{g} / \mathrm{ml}$ poly-Dlysine plus $10 \mu \mathrm{g} / \mathrm{ml}$ of laminin (both from Sigma) and, after settling overnight, incubated with appropriate treatments for 3 days at $37{ }^{\circ} \mathrm{C}$ and $5 \% \mathrm{CO}_{2}$, as described below.

\section{Treatment of DRGN Cultures with BMP4 Peptide}

To establish if BMP4 promoted disinhibited DRGN neurite outgrowth, cultures prepared in 8-well chamber slides as described above were treated with NBA alone (control) or with NBA plus 50, 100, 150 and $200 \mathrm{ng} / \mathrm{ml}$ of BMP4 peptide (Peprotech, London, UK), in the presence of $200 \mu \mathrm{g} / \mathrm{ml} \mathrm{CME}$ [26]. Cultures were incubated with appropriate treatments for 3 days before fixation in $4 \%$ paraformaldehyde and subjected to immunocytochemistry as described below. All slides were masked after treatment for analysis by a second unbiased investigator. Four days later, immunocytochemistry for $\beta$ III-tubulin was then used to quantify DRGN neurite outgrowth as described below. Individual treatments in each experimental run were performed in triplicate and runs were repeated on three independent occasions (total $n=9$ wells/treatment).

\section{Immunocytochemistry of Cultured DRGN}

After 4 days of treatment, DRGN cultures were immersion fixed in $4 \%$ formaldehyde for $10 \mathrm{~min}$ at RT, permeabilised 
Table 2 List of primary and secondary antibodies used in this study

\begin{tabular}{lll}
\hline Antibody & Source & Dilution \\
\hline & \multicolumn{1}{c}{ Primary antibodies } & $1: 400$ \\
Mouse anti-BIII-tubulin & Sigma, Poole, UK & $1: 200$ \\
Rabbit anti-pSmad1 & Cell Signalling Technology, Danvers, MA, USA & $1: 400$ \\
Rabbit anti-BMP4 & Abcam, Cambridge, UK & $1: 400$ \\
Rabbit anti-Noggin & Abcam, Cambridge, UK & $1: 400$ \\
Mouse anti-NF200 & Sigma, Poole, UK & $1: 200$ \\
Mouse anti-GAP-43 & Invitrogen, Paisley, UK & $1: 400$ \\
Rabbit anti-GFAP & Sigma, Poole, UK & $1: 400$ \\
Secondary antibodies & & $1: 400$ \\
Alexa-488 anti-rabbit & Invitrogen, Paisley, UK & $1: 400$ \\
Alexa-488 anti-mouse & Invitrogen, Paisley, UK & $1: 400$ \\
Alexa-594 anti-mouse & Invitrogen, Paisley, UK & \\
Alexa-594 anti-rabbit & Invitrogen, Paisley, UK & \\
\end{tabular}

and non-specific binding blocked using 3\% BSA containing $0.1 \%$ Triton X-100 in PBS. After incubation with mouse anti-ßIII-tubulin antibody (to label DRGN; Table 2) for $1 \mathrm{~h}$ at RT, cells were washed in PBS, incubated with Alexa 488 anti-mouse secondary antibody (Table 2 ) for $1 \mathrm{~h}$ at RT, washed in PBS and mounted using Vectashield containing DAPI (Vector Laboratories, Peterborough, UK) and stored at $4{ }^{\circ} \mathrm{C}$ until required. Negative staining controls were included in each run in which the primary antibody was omitted and used to set the background fluorescence thresholds for each antibody when capturing images.

\section{DRGN Survival and Neurite Outgrowth}

With the experimenter masked to the treatment conditions, mean numbers of $\beta$ III-tubulin ${ }^{+}$DRGN with neurites and mean neurite lengths were quantified in nine quadrants/ well using a Zeiss Axioplan 2 fluorescent microscope equipped with an Axiocam HRc and Axiovision Software (all from Zeiss, Hertfordshire, UK) [25]. The longest neurite was measured using Axiovision from at least 30 DRGN/well/treatment, whilst total DRGN counts to assess survival were made over the entire well for each treatment condition ( $n=3$ wells/treatment, 3 independent repeats; total $n=9$ wells/treatment).

\section{BMP4 Enzyme-Linked Immunosorbent Assay}

The levels of BMP4 in DRG and in the spinal cord lesionsite tissue were detected by ELISA using a rat BMP4 ELISA kit, according to the manufacturer's instructions (ElisaGenie, London, UK). DRG ( $n=6 /$ treatment, 3 independent repeats; total $n=18 \mathrm{DRG} /$ treatment) and an area of T8 spinal cord ( $n=6 /$ treatment, 3 independent repeats; total $n=18$ cords/treatment) that encompassed the lesion site $(1 \mathrm{~cm}$ in length $\times 0.5 \mathrm{~mm}$ centred on the lesion epicentre) were collected, weighed and equal amounts were homogenised in $1 \mathrm{ml}$ of tissue extraction buffer (100 mM Tris, pH 7.4, $150 \mathrm{mM} \mathrm{NaCl,} 1 \mathrm{mM}$ EGTA, 1 mM EDTA, $1 \%$ Triton $\mathrm{X}-100$ and $0.5 \%$ sodium deoxycholate). Samples were kept at $4{ }^{\circ} \mathrm{C}$ for $30 \mathrm{~min}$ before clarification by centrifugation at $13,000 \mathrm{rpm}$ at $4{ }^{\circ} \mathrm{C}$ for $15 \mathrm{~min}$. ELISA was performed on $10 \mu \mathrm{l}$ of each sample, in duplicate and repeated on three independent occasions.

\section{Quantification of DC Axon Regeneration}

Numbers of regenerating axons in the DC were quantified as previously described [19, 27]. Composites of serial parasagittal sections through the entire DC were reconstructed by collecting images of GAP-43-labelled axons in the spinal cord from all serial $50-\mu \mathrm{m}$-thick sections $(\sim 70-80$ sections/ cord; $n=6$ rats/treatment, 3 independent repeats; total $n=18$ rats/group). On each reconstructed composite image, the number of GAP $43^{+}$axons intersecting a dorsoventral line drawn across the cord was counted at intervals of $2 \mathrm{~mm}$ from $4 \mathrm{~mm}$ above to $6 \mathrm{~mm}$ below the lesion site. Axon number was calculated as \% axons seen at $4 \mathrm{~mm}$ above the lesion, where the DC was intact. The distance beyond the epicentre of the lesion towards the rostral end was scored as positive and the caudal end as negative distances.

\section{Electrophysiology}

Compound action potentials (CAP) were recorded at 6 weeks after DC + AAV-Null/BMP4 treatment, as previously described [19, 28]. The treatment status of the animal masked from the investigator, sham controls and animals from $\mathrm{DC}+$ AAV-Null and DC + AAV-BMP4 groups ( $n=6$ rats/group, 3 
Table 3 Microarray analysis to show fold-differences in BMP4/Smad1 pathway genes compared to sham controls in rat DRGN 10 days after DC, SN and $\mathrm{pSN}+\mathrm{DC}$ lesions

\begin{tabular}{|c|c|c|c|c|}
\hline Gene & Description & DC & SN & $\mathrm{pSN}+\mathrm{DC}$ \\
\hline smad 1 & Mothers against decapentaplegic homologue 1 & $1.03 \pm 0.05$ & $3.01 \pm 0.04 * * *$ & $3.19 \pm 0.04 * * *$ \\
\hline smad 2 & Mothers against decapentaplegic homologue 2 & $1.03 \pm 0.05$ & $3.01 \pm 0.04 * * *$ & $3.19 \pm 0.04 * * *$ \\
\hline smad 3 & Mothers against decapentaplegic homologue 3 & $1.11 \pm 0.10$ & $1.04 \pm 0.11$ & $1.06 \pm 0.04$ \\
\hline $\operatorname{smad} 4$ & Mothers against decapentaplegic homologue 4 & $1.09 \pm 0.03$ & $2.01 \pm 0.01 * *$ & $2.00 \pm 0.02 * *$ \\
\hline smad 5 & Mothers against decapentaplegic homologue 5 & $1.01 \pm 0.03$ & $3.58 \pm 0.02 * * *$ & $3.30 \pm 0.03 * * *$ \\
\hline smad 6 & Mothers against decapentaplegic homologue 6 & $1.01 \pm 0.10$ & $1.01 \pm 0.05$ & $1.02 \pm 0.04$ \\
\hline smad 7 & Mothers against decapentaplegic homologue 7 & $1.09 \pm 0.06$ & $1.05 \pm 0.08$ & $1.03 \pm 0.03$ \\
\hline smad 8 & Mothers against decapentaplegic homologue 8 & $0.99 \pm 0.13$ & $2.01 \pm 0.02 * *$ & $2.30 \pm 0.03 * *$ \\
\hline $\operatorname{tg} f \beta 1$ & Transforming growth factor $\beta 1$ & $1.09 \pm 0.10$ & $1.41 \pm 0.06$ & $1.55 \pm 0.01$ \\
\hline $\operatorname{tg} f \beta 2$ & Transforming growth factor $\beta 2$ & $1.09 \pm 0.10$ & $2.41 \pm 0.16$ & $2.35 \pm 0.08$ \\
\hline bmp-2 & Bone morphogenetic protein 2 & $1.01 \pm 0.02$ & $1.41 \pm 0.06$ & $1.55 \pm 0.03$ \\
\hline bmp-4 & Bone morphogenetic protein 4 & $1.09 \pm 0.10$ & $6.41 \pm 0.16^{* * * *}$ & $6.66 \pm 0.11 * * *$ \\
\hline bmp-7 & Bone morphogenetic protein 7 & $1.00 \pm 0.01$ & $1.09 \pm 0.10$ & $1.06 \pm 0.02$ \\
\hline smurf1 & Bone morphogenetic protein 7 & $1.00 \pm 0.01$ & $1.09 \pm 0.10$ & $1.06 \pm 0.02$ \\
\hline smurf 2 & Bone morphogenetic protein 7 & $1.04 \pm 0.11$ & $1.03 \pm 0.09$ & $1.01 \pm 0.08$ \\
\hline nogg & Noggin & $1.01 \pm 0.08$ & $-2.01 \pm 0.09 * *$ & $-2.05 \pm 0.15^{* *}$ \\
\hline
\end{tabular}

Means \pm SEM are shown from four different samples run in duplicate. $* * P<0.001$, $* * * P<0.0001$. Fold difference of $>2$ were considered significant

independent repeats; total $n=18$ rats/group) were deeply anaesthetised using 5\% isofluorane, and deep anaesthesia was maintained with $1.5 \%$ isofluorane for the duration of the experiment, verified by the absence of a withdrawal reflex to a peripheral pinch. Heart rate of approximately 360 beats/min was carefully monitored and body temperature was controlled using a feedback-controlled thermal blanket set at $37{ }^{\circ} \mathrm{C}$. Rats were fixed in a Kopf stereotaxic apparatus (Kopf Instruments, Tujunga, CA, USA), a midline incision was made through the skin, a laminectomy was performed and the dura was cut to expose the thoracic and lumbar spinal cord regions. Spinal cords were bathed in warm mineral oil $\left(37^{\circ} \mathrm{C}\right)$. Silver wire electrodes $\left(0.01^{\prime \prime}\right.$ diameter; A-M Systems, Carlsborg, WA, USA) insulated except at the tip were used to stimulate the DC axons at L1/2 and record CAP at T10-T9 at the surface of the midline spinal cord. Pancuronium bromide $(0.3 \mathrm{mg} / \mathrm{kg}$, Sigma) was injected intraperitoneally to minimise muscular contractions throughout the experiment. The signal from the recording electrode was amplified with filters set at $300-3000 \mathrm{~Hz}$, collected and Spike 2 software was used for data analysis (Cambridge Electronic Design, Cambridge, UK). Stimulating single current pulses $(0.05 \mathrm{~ms})$ were applied in increasing increments $(0.2,0.3,0.6,0.8$ and $1.1 \mathrm{~mA})$, recorded at the detecting electrode and the amplified signals were analysed using Spike 2 software (Cambridge Electronic Design). CAP amplitudes and areas were then calculated. At the end of each experiment, the dorsal half of the spinal cord was transected between stimulating and recording electrodes to confirm CAP abolition.

\section{Functional Testing}

Tape removal (sensory) and horizontal ladder crossing (locomotor) functional tests after DC lesions and treatment were carried out as described previously by us and others $[18,19]$. Functional deficits using the DC injury model are mild, and hence, we used the horizontal ladder crossing and tape removal tests as two of the five tests described by Fagoe et al. [18] to reliably detect functional deficits after injury. Fagoe et al. [18] and we [19] have shown previously that functional deficits can be reliably detected using these specific tests in the DC injury model. Briefly, animals ( $n=6$ rats/group, 3 independent repeats; total $n=18 \mathrm{rats} /$ group) received training to master traversing the rope and ladder for 2 weeks before functional testing. All functional tests were performed 2-3 days before injury to establish baseline parameters. Animals were then tested 2 days after DC lesion and then weekly for 6 weeks at the same time of day and each test performed for three individual trials. For the horizontal ladder test, the number of slips for each run was averaged by the total number of steps to calculate the mean error rate. For the tape removal test, the time it took for the animals to detect and remove a piece of sticky tape attached to its 

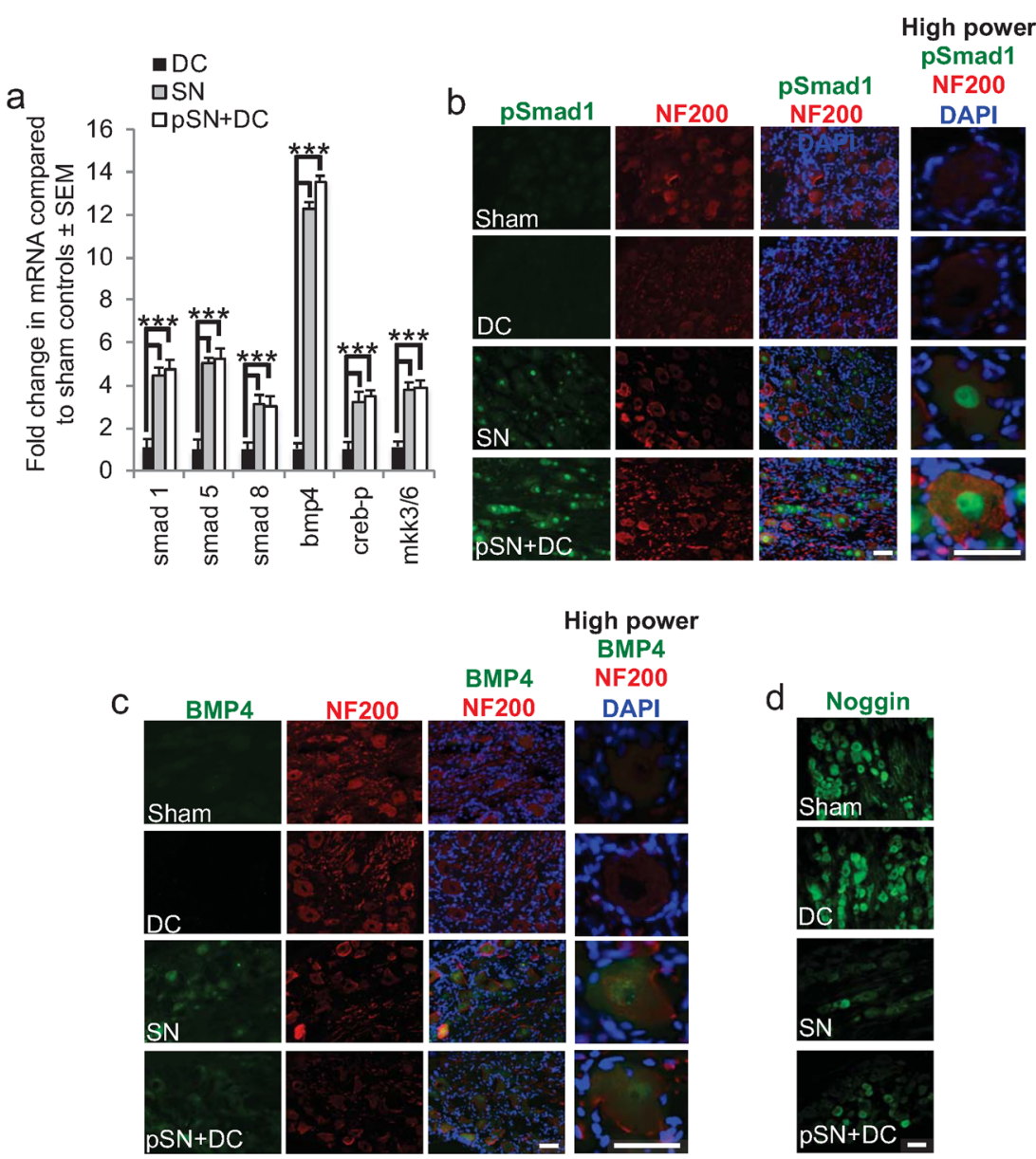

Fig. 2 Changes in Smad1/BMP4 signalling pathway. a Q-PCR confirmed good correlation between microarray and Q-PCR data. b Immunohistochemistry for pSmad1 (green) in sections of regenerating (SN, pSN + DC) and non-regenerating (IC, DC) NF200 ${ }^{+}$DRGN (red) and of satellite cells (DAPI ${ }^{+}$nuclei-blue). High levels of pSmad1 immunoreactivity were detected in occasional nuclei of regenerating $\mathrm{SN}$ and many nuclei of $\mathrm{pSN}+\mathrm{DC}$ DRGN. c Immunohistochemistry for BMP4 (green) in sections of regenerating $(\mathrm{SN}, \mathrm{pSN}+\mathrm{DC})$ and non-regenerating
(IC, DC) NF200 ${ }^{+}$DRGN (red) and of satellite cells (DAPI ${ }^{+}$nuclei-blue). BMP4 immunoreactivity was detected in most regenerating SN and pSN + DC DRGN. d Immunohistochemistry for Noggin in sections of regenerating $(\mathrm{SN}, \mathrm{pSN}+\mathrm{DC})$ and non-regenerating (IC, DC) DRGN. Noggin immunoreactivity was highest in sham and DC whilst lower levels of immunoreactivity were detected in regenerating SN and pSN + DC DRGN. Scale bars in $\mathbf{b}-\mathbf{d}=50 \mu \mathrm{m}$ extended hind paw was recorded and used to calculate the mean sensing time.

\section{Statistical Analyses}

Where indicated, significant differences on means \pm SEM were calculated between samples using SPSS Version 22 (IBM, NJ, USA) one-way analysis of variance (ANOVA) with post hoc testing using Dunnet's method.

For the ladder crossing functional test, data was analysed using R package (www.r-project.org) as described previously $[18,19]$. Briefly, whole time-course testing of lesioned and sham-treated animals were compared using binomial generalised linear mixed models (GLMM), fitted in R using package lme 4 with the glmer function and $P$ values calculated using parametric bootstrap. For the tape removal test, linear mixed models (LMM) were calculated by model comparison using the package pbkrtest, with the Kenward-Roger method [18, 19]. Individual time-points were also compared using independent sample $t$ test without correction.

\section{Results}

\section{BMP4/Smad1 Pathway Activation in DRGN}

Microarray data showed that the levels of mRNA for smad1, smad2, smad4, smad5, smad 8 and bmp 4 were all up-regulated between 2.0- and 6.7-fold compared to sham controls, whilst noggin was 2-fold down-regulated, in the DRG from both the 
$\mathrm{SN}$ and pSN + DC models (Table 3), but there was no change in these mRNA levels in DRG from the DC model. Confirmation of the heightened levels of BMP4/Smad1 mRNA in regenerating DRGN was provided by Q-PCR, which reflected changes observed by microarray (Fig. 2a). These results indicated that the BMP4/Smad1 signalling pathway was highly active in DRG after SN and pSN + DC injury when both SN and DC DRGN axonal projections were regenerating.

\section{Immunohistochemistry of Smad1, BMP4 and Noggin}

In both sham controls and DC models, pSmad1 (Fig. 2b) and $\mathrm{BMP}^{+}{ }^{+}$immunoreactivity (Fig. 2c) were not detected in DRG cells, but in SN and pSN + DC models, both were expressed in DRGN soma and nuclei, the former in greater amounts than the latter, but both proteins were absent from satellite cells. On the other hand, Noggin ${ }^{+}$immunoreactivity was present in DRGN somata in sham controls and DC, but lower levels were detected in regenerating $\mathrm{SN}$ and $\mathrm{pSN}+\mathrm{DC}$ models (Fig. 2d). These results confirmed the highly activated state of BMP4/Smad1 signalling in DRGN of the regenerating SN and $\mathrm{pSN}+\mathrm{DC}$ models.

\section{BMP4 Disinhibited DRGN Neurite Outgrowth In Vitro and DC Axon Growth In Vivo, Independent of mTOR}

There was no DRGN neurite outgrowth in control-untreated DRG cultures prepared from intact rats in the presence of inhibitory concentrations of CME (Fig. 3a), whilst positive control cultures treated with FGF2 showed significant disinhibited neurite outgrowth (not shown). However, increasing the concentration of BMP4 peptide, in the presence of CME, disinhibited DRGN neurite outgrowth, increasing mean DRGN neurite length (Fig. 3a, b) and the \% DRGN with neurites (Fig. 3c) to a maximum at a concentration $100 \mathrm{ng} / \mathrm{ml}$, beyond which disinhibited DRGN neurite outgrowth declined. These results showed that activation of the BMP4/Smad1 signalling pathway promoted DRGN survival and disinhibited neurite outgrowth in the presence of CME.

Intra-DRG injection of AAV-BMP4 significantly increased BMP4 mRNA levels by $7.6 \pm 0.3$-fold (Fig. 3d) whilst BMP4 protein levels also increased significantly to $642 \pm 83 \mathrm{ng} / \mathrm{mg}$ of tissue, compared to $9.7 \pm 1.2 \mathrm{ng} / \mathrm{mg}$ of tissue after $\mathrm{DC}+$ AAV-Null treatment (Fig. 3e). These results demonstrated that significant titres of BMP4 mRNA and protein were induced in DRGN after intra-DRG injection of AAV-BMP.

In DC + AAV-Null-treated rats (Fig. 4a-c), spinal cord cavitation (\#) was observed at the lesion site (*) with $\mathrm{GFAP}^{+}$immunoreactivity surrounding the lesion cavity (Fig. 4a), with little or no GAP- $43^{+}$(red) regenerating axons observed (Fig. $4 \mathrm{~b}, \mathrm{c}$ ). However, intra-DRG injection of AAV-BMP4 (Fig. 4df) not only showed infiltration of GFAP ${ }^{+}$astrocytes (green) into the lesion site (Fig. 4d, d(i) = high power of boxed region in Fig. 3d) but also promoted regeneration of ascending GAP43 ${ }^{+}$ DC axons (red) into preserved tissue around areas of cavitation (\#) about the lesion site (Fig. 4e, f; e(i), f(i)= high power of boxed regions in Fig. 4e, f, respectively). Quantification of the total number of GAP43 ${ }^{+}$axons (red) traversing the lesion site showed that $27 \pm 4.4,19.2 \pm 2.2,14.7 \pm 2.4$ and $11.33 \pm 1.5 \%$
Fig. 3 BMP4 disinhibits DRGN neurite outgrowth in vitro. a Escalating concentrations of BMP4 up to $100 \mathrm{ng} / \mathrm{ml}$ increased; b the length of the longest neurite; and c \% DRGN with neurites. d Transduction with AAV-BMP4 significantly increased the levels of BMP4 mRNA by $\sim 8$-fold $>$ $\mathrm{DC}+\mathrm{AAV}-\mathrm{Null}$ injection. $\mathrm{e}$ ELISA confirmed that AAVBMP4 significantly increased the titres of BMP4 in DRG a

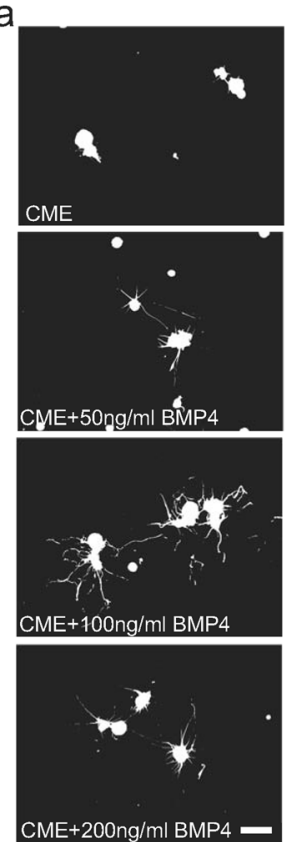

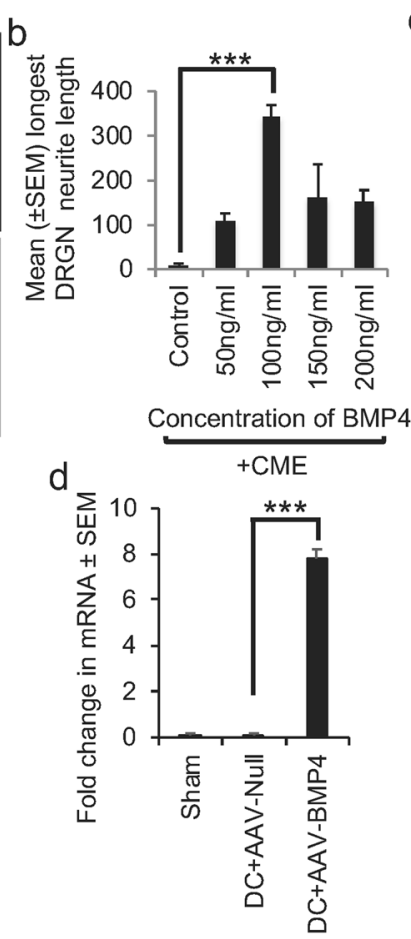

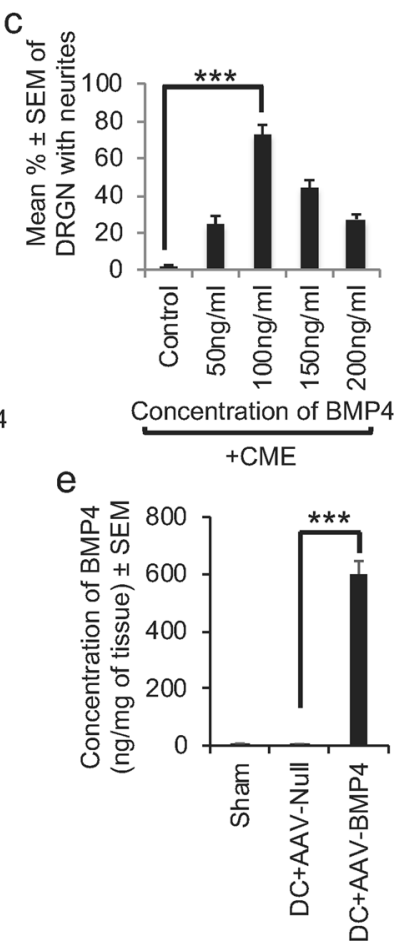


Fig. 4 BMP4 promotes axon regeneration in an in vivo rat model that cavitates. a-c Treatment with DC + AAV-Null leads to cavity (\#) formation at the lesion site (*) with no evidence of axon regeneration. d-f AAVBMP4 enhances DC axon regeneration despite the presence of cavities (\#), detected by GAP43 ${ }^{+}$ staining (red) with GFAP $^{+}$astrocytes (green) also infiltrating the lesion site (*). c, $\mathbf{f}$ Merged images to show GFAP (green) and GAP43 (red) double staining with $\mathrm{DAPI}^{+}$nuclei (blue). Inset d(i), e(i) and $\mathbf{f ( i )}=$ higher power views of the boxed regions in $\mathbf{d}-\mathbf{f}$, respectively. g Quantification of DC axon regeneration at the lesion site, rostral and caudal to the lesion. $* * *=P<0.0001$, ANOVA. $* *=P<0.001 ; *=P<0.05$, ANOVA. Scale bars in a-f and d(i) $\mathbf{f ( i )}=100 \mu \mathrm{m}$

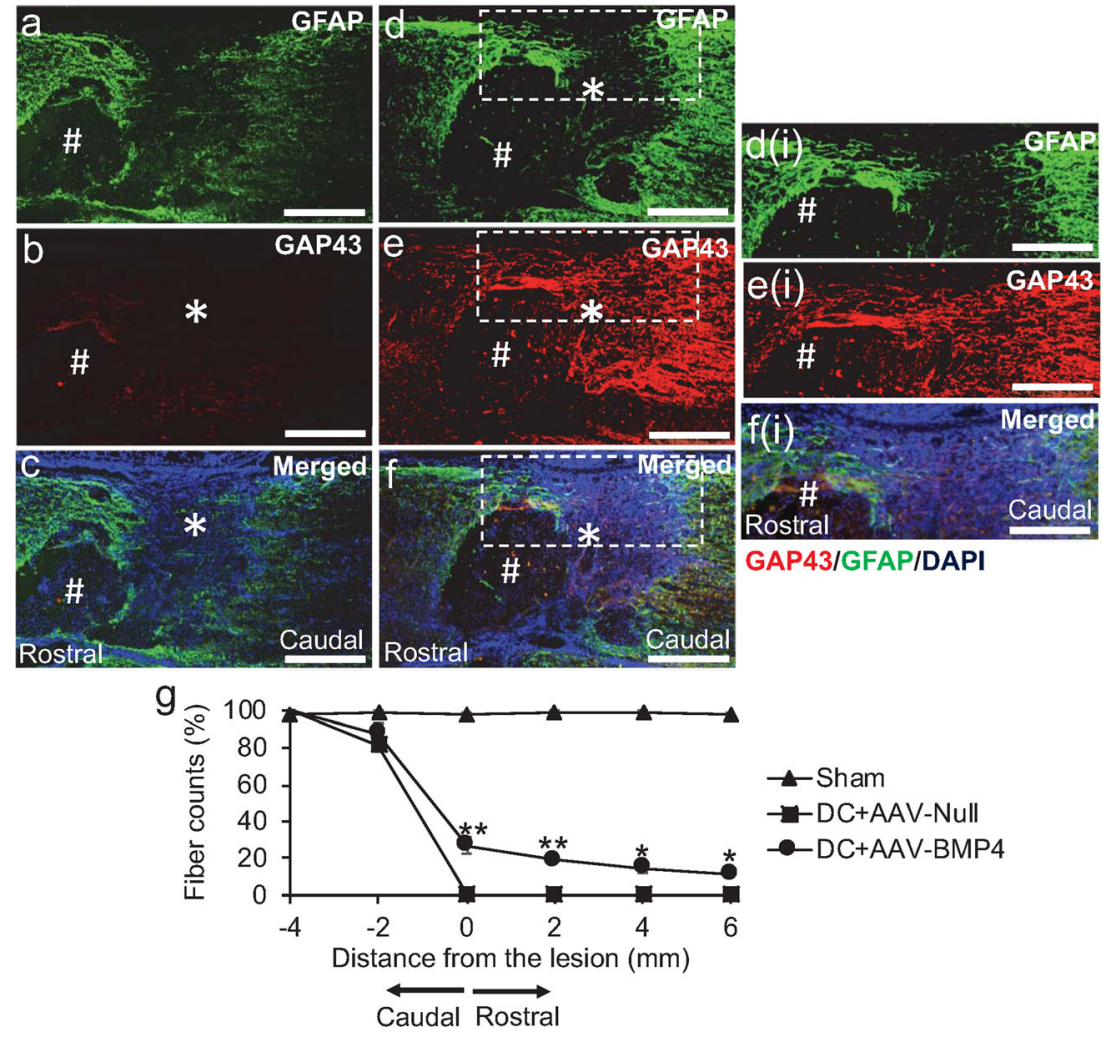

of axons regenerated $0,2,4$ and $6 \mathrm{~mm}$ beyond the lesion site, respectively, in $\mathrm{DC}+\mathrm{AAV}-\mathrm{BMP} 4-$ treated rats, whilst no axons were present in $\mathrm{DC}+\mathrm{AAV}-\mathrm{Null}$-treated groups (Fig. 3g). These results suggested that AAV-BMP4 promoted DRGN axon regeneration in long-tract ascending pathways of the rat spinal cord, despite the presence of cavities.

\section{AAV-BMP4 Promoted Electrophysiological Recovery Across the DC Lesion Site}

Superimposed CAP traces from representative animals from the sham control, DC + AAV-Null and DC + AAV-BMP4 groups (Fig. 5a) showed that in the DC + AAV-Null groups, the mean amplitude of the CAP wave was significantly attenuated compared to that of the sham control group (Fig. 5b). The mean CAP amplitude was significantly reduced in the DC + AAV-Null group, compared to sham controls (Fig. 5b). However, significantly larger CAP amplitudes were observed in DC + AAV-BMP4-treated rats at all stimulation intensities, compared to those in the $\mathrm{DC}+\mathrm{AAV}-\mathrm{Null}$ treatment group $(P<0.001$; Fig. 5b). In sham controls, CAP area $(0.65 \pm$ $0.1 \mathrm{mV} \times \mathrm{ms})$ was reduced to $8.0 \pm 7.8 \%$ of the CAP area in $\mathrm{DC}+\mathrm{AAV}-\mathrm{Null}$-treated groups $(0.04 \pm 0.05 \mathrm{mV} \times \mathrm{ms})$ (Fig. 5c). CAP area in the DC + AAV-BMP4 group was significantly larger $(P<0.001)$ than in the $\mathrm{DC}+\mathrm{AAV}-\mathrm{Null}$ group and was increased to $61.5 \pm 10 \%$ of that of the sham control group (Fig. 5c). These results showed that in the AAV-BMP4 group, axons conduct action potentials across the lesion site and that conduction amplitudes had returned to $>60 \%$ of the original intact spinal amplitudes, despite the presence of cavities.

\section{AAV-BMP4 Promoted Functional Recovery}

The mean sensing time for the tape removal test was between 12 and $25 \mathrm{~s}$ in sham-treated animals throughout the 6 weeks of testing (Fig. 5d). We observed a significant increase of $77 \pm$ $22 \mathrm{~s}$ at 2 days in DC + AAV-Null-treated groups in the time it takes to sense and remove the adhesive tape decreasing to 39$52 \mathrm{~s}$ from 4 weeks onwards. However, in DC + AAV-BMP4treated animals, the mean sensing time was significantly less at 2 days after injury when compared to DC + AAV-Null-treated animals, taking only $39 \pm 6 \mathrm{~s}$ to detect and remove the adhesive tape $(P<0.001$, independent sample $t$ test). By 3 weeks after DC lesion, the mean sensing time in $\mathrm{DC}+$ AAV-BMP4-treated animals was no different to that of sham-treated control animals and significantly improved compared to DC + AAV-Null-treated animals $(P<0.001$, independent sample $t$ test). Over the whole-time course, there was a significant reduction in the time taken to sense and remove the adhesive tape in DC + AAV-BMP4-treated compared to DC + AAV-Null-treated animals (linear mixed model, $P<0.001$ ).

Over a 6-week testing period, there was a significant increase in the error rates during horizontal ladder walking (generalised linear mixed model, $P<0.0011$ ) (Fig. 5e) in DC+ AAV-Null-treated compared to DC + AAV-BMP4-treated animals. The mean error ratio was significantly lower in $\mathrm{DC}+$ 
Fig. 5 AAV-BMP4 promotes preservation of spinal CAP across the lesion site and functional recovery. a Superimposed CAP traces from representative animals in sham, DC + AAV-Null and $\mathrm{DC}+\mathrm{AAV}-\mathrm{BMP} 4$ treatment groups. b Compared to sham control, CAP amplitudes (mV) were greatly attenuated in the $\mathrm{DC}+\mathrm{AAV}-\mathrm{Null}$ group, but were significantly improved in the $\mathrm{DC}+\mathrm{AAV}-\mathrm{BMP} 4$ group $(P<0.001$, ANOVA). c Mean $\mathrm{CAP}$ area at different stimulus intensities record from sham was significantly attenuated in the DC + AAV-Null group, but significantly improved in the DC + AAV-BMP4 compared to the $\mathrm{DC}+\mathrm{AAV}-\mathrm{Null}$ group $(* * P<0.001$, ANOVA). d Mean sensing time for the tape removal test and mean error ratios for the $\mathbf{e}$ horizontal ladder walking tests show significant recovery of function after AAV-BMP4 treatment. $\# P<0.05 ; \# \# P<0.001$, generalised linear models. $* * P<0.001$, independent sample $t$ test
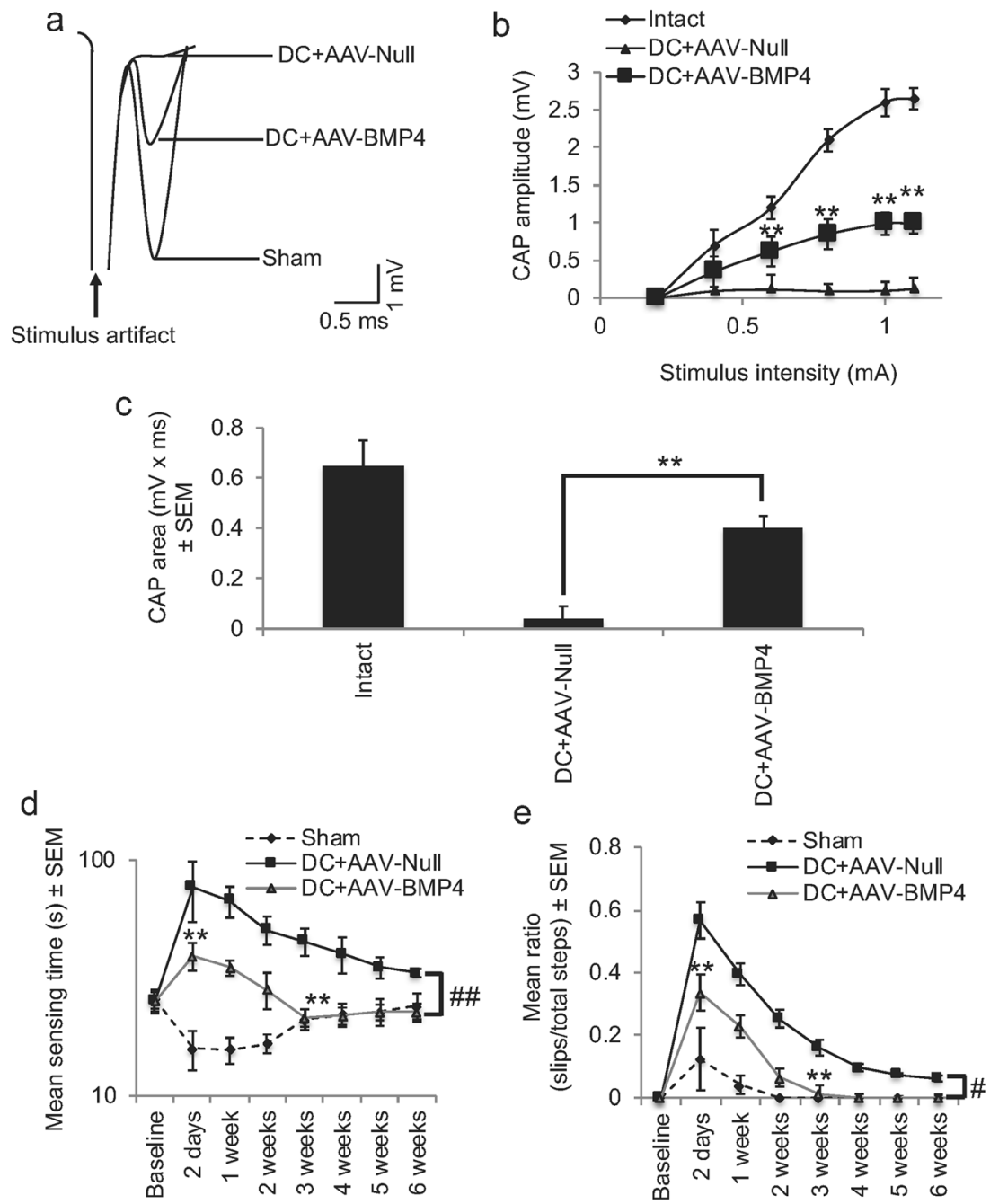

AAV-BMP4 compared to DC + AAV-Null-treated animals at 2 days after injury $(P<0.001$, independent sample $t$ test $)$ and at $2-3$ weeks $(P<0.001$, independent sample $t$ test) by which time the error rate was no different to that of sham controls. A significant functional deficit remained in DC + AAV-Nulltreated rats throughout the duration of the test. These results demonstrated that AAV-BMP4 promoted significant sensory and locomotor function recovery after DC injury in the rat, despite the presence of cavities.

\section{Discussion}

In this study, we investigated the relative contribution of signalling through the BMP4/Smad1 pathway in promoting long-tract DRGN axon regeneration after DC injury in the rat model that cavitates and showed by microarray and immunohistochemistry analyses that components of the BMP4/ Smad1 pathway were highly correlative with the regenerative outcome seen after DC transection. For example, BMP4 and
Smad $1 \mathrm{mRNA}$ and protein were highly upregulated in both regenerating paradigms whilst expression levels of the BMP4 suppressor Noggin were attenuated. Treatment of DRGN cultures with BMP4 significantly disinhibited neurite outgrowth in the presence of inhibitory concentrations of $\mathrm{CME}$, whilst AAV8-mediated delivery of BMP4 in the rat in vivo promoted DC axon regeneration and electrophysiological, sensory and locomotor improvements after DC injury, despite the presence of cavities.

The PTEN/mTOR pathway has emerged as one key determinant in regenerative success in the adult RGC [29-31] and corticospinal tract $[4,32,33]$. However, pten deletion not only promotes axon regeneration through mTOR-dependent mechanisms [30] but also through mTOR-independent mechanisms [34]. Numerous other studies have shown that mTOR activity is not required for peripheral nerve regeneration [35-37]. Instead, peripheral sensory axon regeneration is thought to be mediated by PI3K signalling via GSK3 inactivation and subsequent gene expression, independent of mTORmediated protein synthesis $[37,38]$. 
In DRGN, a possible PI3K/Akt axogenic signalling route, independent of mTOR, is through the BMP4/Smad1 pathway which influences a broad spectrum of intracellular signalling pathways $[12,39,40]$ including MAPK, GSK3- $\beta$, PI3K and Akt. The DRGN axon growth promoted by NTF/Trk binding and subsequent activation of the MAPK and PI3K/Akt effector pathways is arrested after suppression of BMP [13] probably because, in the absence of Smad1, transcription of the NTF effectors Erk1/2 is blocked [10]. Within the BMP/Smad pathway, raised BMP4 and Smad1, 2, 4, 5, 8 mRNA and lowered Noggin mRNA levels correlated with complimentary changes in BMP4, pSmad1 and Noggin protein in DRGN in the DC, SN and pSN + DC models. Moreover, our observation that BMP4 disinhibited DRGN neurite growth on a CME substrate in culture agrees with previous findings [15]. Both SN axotomy and intra-DRG injection of BMP2/4 protein activates Smad1 in DRGN and enhances DRGN neurite outgrowth, whilst DC transection fails to activate the Smad1 pathway [14].

Down-regulation of the BMP/Smad1 pathway occurs during the age-related decline in axon growth potential and, in adults, blockade of BMP signalling, by either pharmacological inhibition or knockdown of Smad1, arrests the initiation and elongation of DRGN neurites [13], whereas activation of Smad1 by intrathecal injection of AAV-BMP4 stimulates DRGN axon regeneration through mouse DC lesions [13]. However, BMP control of growth cone mobility through regulation of actin dynamics is independent of Smad1 and involves direct interaction between the tail region of BMPRII and LIMK [41-44]. Levels of Noggin mRNA were reduced in the $\mathrm{SN}$ and $\mathrm{pSN}+\mathrm{DC}$ axon regenerating paradigms but not in the non-regenerating DC, agreeing with findings that Noggin inhibits BMP signalling by blocking type I/II BMPR binding sites [45] and reducing DRGN neurite outgrowth. Conversely, suppression of Noggin potentiates $\mathrm{SN}$ axon regeneration in vivo [15].

Despite contradictory reports that BMP4 inhibits axon regeneration by promoting hypertrophic scarring [46] and that Noggin promotes axon growth $[15,47]$ in the spinal cord, we and others [13] have demonstrated DC axon regeneration and functional recovery after delivery to DRGN of either BMP4 peptide or AAV8-BMP4 after intra-DRG and intrathecal injection in both mouse and rat. Moreover, there was constitutive expression of Noggin in DRGN in the DC, but a 2-fold reduction in the $\mathrm{SN}$ and $\mathrm{pSN}+\mathrm{DC}$ regenerating models, indicating that future delivery to DRGN of a combination of AAV8-BMP4 with a Noggin antagonist is expected to significantly enhance DC axon regeneration further and promote significant functional recovery, as shown by the preservation of CAP and improvements in ladder walking and tape removal tests. Our electrophysiological data recorded cord dorsum potentials, which not only measured dorsal column activity but may have detected signals from diverse sources. For example, CDP is an evoked spinal cord field potential that arises in the dorsal horn interneurons of the spinal cord segments receiving inputs from a stimulated peripheral nerve and can originate from proximal sensory nerve, dorsal nerve root and spinal cord dorsal horn function [48]. Therefore, it is likely that some improvements may be due to preservation of these pathways in the AAV-BMP4-treated groups.

The beneficial effects of BMP4 delivery demonstrated in our study are significant since previous work by Parikh et al. (2011) using the same AAV8-BMP4 promoted DC axon regeneration and functional recovery in the mouse, which does not cavitate but instead fills the lesion site with fibrotic tissue $[16,49]$. SCI in the rat normally results in large cystic cavities that extend rostrally and caudally to the original lesion site [50]. Pathologically, rat SCI is more similar to that seen in humans where spinal cord atrophy, myelomalacia, cyst and syrinx formation occurs [51]. Therefore, our demonstration of the benefits of BMP4 treatment after SCI in the rat is translationally more relevant to the human condition.

Although we used AAV8 to deliver BMP4, which is not considered translational since transgenes were injected 1 week before DC injury, the study does demonstrate proof-ofprinciple that activation of the BMP4/Smad1 pathway is important in promoting long-tract ascending DC axon regeneration after injury. However, we have shown in the rat DC lesion model that a non-viral delivery vector, in vivo-JetPEI, delivered plasmid DNA with the same efficiency of transduction as AAV and without activation of non-specific interferon responses, promoting similar DC axon regeneration, electrophysiological and functional recovery [19]. We expect that the same non-viral delivery vector can be used to safely deliver BMP4 and activate the BMP/Smad1 signalling pathway, making the approach translationally relevant.

Thus, we have provided in vitro and in vivo evidence that the BMP4/Smad1 pathway was activated in DRGN in the regenerating $\mathrm{SN}$ and $\mathrm{pSN}+\mathrm{DC}$ models but not in the non-regenerating DC model. In vitro, BMP4 peptide disinhibited significant DRGN neurite outgrowth and, in vivo, AAV8-BMP4 promoted DC axon regeneration and functional recovery without the need for an SN preconditioning lesion, in a rat model of SCI that cavitates like in humans. We conclude that BMP4 over-expression promoted significant DRGN axon regeneration and enhanced recovery of lost function in the lesioned DC and may be a potential therapy for SCI patients.

Funding Information Funding was provided by a research development fund to ZA by the University of Birmingham. The Biotechnology and Biological Sciences Research Council (UK), grant no. G181986 funded the original microarray study. 


\section{Compliance with Ethical Standards}

All surgery was performed in strict accordance to the guidelines of both the UK Animals Scientific Procedures Act, 1986 and the Revised European Directive 1010/63/EU. Experiments were licenced by the UK Home Office and ethically approved by the University of Birmingham's animal welfare and ethical review board. Experiments also conformed to the recommendations of the use of animals by the Federation of the European Laboratory Animal Science Associations.

Conflict of Interest The authors declare that they have no conflicts of interest.

\section{References}

1. Atwal JK, Massie B, Miller FD, Kaplan DR (2000) The TrkB-She site signals neuronal survival and local axon growth via MEK and P13-kinase. Neuron 27(2):265-277

2. Gallo G, Letourneau PC (1998) Localized sources of neurotrophins initiate axon collateral sprouting. J Neurosci 18(14):5403-5414

3. Ming G, Song H, Berninger B, Inagaki N, Tessier-Lavigne M, Poo M (1999) Phospholipase C-gamma and phosphoinositide 3-kinase mediate cytoplasmic signaling in nerve growth cone guidance. Neuron 23(1):139-148

4. Liu K, Lu Y, Lee JK, Samara R, Willenberg R, Sears-Kraxberger I, Tedeschi A, Park KK et al (2010) PTEN deletion enhances the regenerative ability of adult corticospinal neurons. Nat Neurosci 13(9):1075-1081. https://doi.org/10.1038/nn.2603

5. Richardson PM, Issa VM (1984) Peripheral injury enhances central regeneration of primary sensory neurones. Nature 309(5971):791793

6. Neumann S, Woolf CJ (1999) Regeneration of dorsal column fibers into and beyond the lesion site following adult spinal cord injury. Neuron 23(1):83-91

7. Skene JH (1989) Axonal growth-associated proteins. Annu Rev Neurosci 12:127-156. https://doi.org/10.1146/annurev.ne.12. 030189.001015

8. Bosse F, Kury P, Muller HW (2001) Gene expression profiling and molecular aspects in peripheral nerve regeneration. Restor Neurol Neurosci 19(1-2):5-18

9. Rossi F, Gianola S, Corvetti L (2007) Regulation of intrinsic neuronal properties for axon growth and regeneration. Prog Neurobiol 81(1):1-28. https://doi.org/10.1016/j.pneurobio.2006.12.001

10. Finelli MJ, Murphy KJ, Chen L, Zou H (2013) Differential phosphorylation of Smad1 integrates BMP and neurotrophin pathways through Erk/Dusp in axon development. Cell Rep 3(5):1592-1606. https://doi.org/10.1016/j.celrep.2013.04.011

11. Beck SE, Carethers JM (2007) BMP suppresses PTEN expression via RAS/ERK signaling. Cancer Biol Ther 6(8):1313-1317

12. Guo X, Wang XF (2009) Signaling cross-talk between TGF-beta/ BMP and other pathways. Cell Res 19(1):71-88. https://doi.org/10. 1038/cr.2008.302

13. Parikh P, Hao Y, Hosseinkhani M, Patil SB, Huntley GW, TessierLavigne M, Zou H (2011) Regeneration of axons in injured spinal cord by activation of bone morphogenetic protein/Smad1 signaling pathway in adult neurons. Proc Natl Acad Sci U S A 108(19):E99E107. https://doi.org/10.1073/pnas.1100426108

14. Zou H, Ho C, Wong K, Tessier-Lavigne M (2009) Axotomyinduced Smad 1 activation promotes axonal growth in adult sensory neurons. J Neurosci 29(22):7116-7123. https://doi.org/10.1523/ JNEUROSCI.5397-08.2009

15. Ma CH, Brenner GJ, Omura T, Samad OA, Costigan M, Inquimbert P, Niederkofler V, Salie R et al (2011) The BMP coreceptor RGMb promotes while the endogenous BMP antagonist noggin reduces neurite outgrowth and peripheral nerve regeneration by modulating BMP signaling. J Neurosci 31(50):18391-18400. https://doi.org/ 10.1523/JNEUROSCI.4550-11.2011

16. Surey S, Berry M, Logan A, Bicknell R, Ahmed Z (2014) Differential cavitation, angiogenesis and wound-healing responses in injured mouse and rat spinal cords. Neuroscience 275:62-80. https://doi.org/10.1016/j.neuroscience.2014.06.003

17. Jacques SJ, Ahmed Z, Forbes A, Douglas MR, Vigenswara V, Berry M, Logan A (2012) AAV8(gfp) preferentially targets large diameter dorsal root ganglion neurones after both intra-dorsal root ganglion and intrathecal injection. Mol Cell Neurosci 49(4):464 474. https://doi.org/10.1016/j.mcn.2012.03.002

18. Fagoe ND, Attwell CL, Eggers R, Tuinenbreijer L, Kouwenhoven D, Verhaagen J, Mason MR (2016) Evaluation of five tests for sensitivity to functional deficits following cervical or thoracic dorsal column transection in the rat. PLoS One 11(3):e0150141. https://doi.org/10.1371/journal.pone.0150141

19. Almutiri S, Berry M, Logan A, Ahmed Z (2018) Non-viralmediated suppression of AMIGO3 promotes disinhibited NT3mediated regeneration of spinal cord dorsal column axons. Sci Rep 8(1):10707. https://doi.org/10.1038/s41598-018-29124-z

20. Lagord C, Berry M, Logan A (2002) Expression of TGFbeta2 but not TGFbetal correlates with the deposition of scar tissue in the lesioned spinal cord. Mol Cell Neurosci 20(1):69-92. https://doi. org/10.1006/mene.2002.1121

21. Ahmed Z, Read ML, Berry M, Logan A (2010) Satellite glia not DRG neurons constitutively activate EGFR but EGFR inactivation is not correlated with axon regeneration. Neurobiol Dis 39(3):292300. https://doi.org/10.1016/j.nbd.2010.04.013

22. Read ML, Mir S, Spice R, Seabright RJ, Suggate EL, Ahmed Z, Berry M, Logan A (2009) Profiling RNA interference (RNAi)-mediated toxicity in neural cultures for effective short interfering RNA design. J Gene Med 11(6):523-534. https://doi.org/10.1002/jgm. 1321

23. Ahmed Z, Bansal D, Tizzard K, Surey S, Esmaeili M, Gonzalez AM, Berry M, Logan A (2014) Decorin blocks scarring and cystic cavitation in acute and induces scar dissolution in chronic spinal cord wounds. Neurobiol Dis 64:163-176. https://doi.org/10.1016/j. nbd.2013.12.008

24. Neumann S, Bradke F, Tessier-Lavigne M, Basbaum AI (2002) Regeneration of sensory axons within the injured spinal cord induced by intraganglionic cAMP elevation. Neuron 34(6):885-893

25. Ahmed Z, Dent RG, Suggate EL, Barrett LB, Seabright RJ, Berry M, Logan A (2005) Disinhibition of neurotrophin-induced dorsal root ganglion cell neurite outgrowth on CNS myelin by siRNAmediated knockdown of NgR, p75NTR and rho-a. Mol Cell Neurosci 28(3):509-523. https://doi.org/10.1016/j.mcn.2004.11.002

26. Ahmed Z, Dent RG, Leadbeater WE, Smith C, Berry M, Logan A (2005) Matrix metalloproteases: Degradation of the inhibitory environment of the transected optic nerve and the scar by regenerating axons. Mol Cell Neurosci 28(1):64-78. https://doi.org/10.1016/j. men.2004.08.013

27. Hata K, Fujitani M, Yasuda Y, Doya H, Saito T, Yamagishi S, Mueller BK, Yamashita T (2006) RGMa inhibition promotes axonal growth and recovery after spinal cord injury. J Cell Biol 173(1): 47-58. https://doi.org/10.1083/jcb.200508143

28. Hains BC, Saab CY, Lo AC, Waxman SG (2004) Sodium channel blockade with phenytoin protects spinal cord axons, enhances axonal conduction, and improves functional motor recovery after contusion SCI. Exp Neurol 188(2):365-377. https://doi.org/10.1016/j. expneurol.2004.04.001

29. de Lima S, Koriyama Y, Kurimoto T, Oliveira JT, Yin Y, Li Y, Gilbert HY, Fagiolini M et al (2012) Full-length axon regeneration in the adult mouse optic nerve and partial recovery of simple visual behaviors. Proc Natl Acad Sci U S A 109(23):9149-9154. https:// doi.org/10.1073/pnas.1119449109 
30. Park KK, Liu K, Hu Y, Smith PD, Wang C, Cai B, Xu B, Connolly $\mathrm{L}$ et al (2008) Promoting axon regeneration in the adult CNS by modulation of the PTEN/mTOR pathway. Science 322(5903):963966. https://doi.org/10.1126/science.1161566

31. Sun F, Park KK, Belin S, Wang D, Lu T, Chen G, Zhang K, Yeung $\mathrm{C}$ et al (2011) Sustained axon regeneration induced by co-deletion of PTEN and SOCS3. Nature 480(7377):372-375. https://doi.org/ 10.1038/nature10594

32. Danilov CA, Steward O (2015) Conditional genetic deletion of PTEN after a spinal cord injury enhances regenerative growth of CST axons and motor function recovery in mice. Exp Neurol 266: 147-160. https://doi.org/10.1016/j.expneurol.2015.02.012

33. Zukor K, Belin S, Wang C, Keelan N, Wang X, He Z (2013) Short hairpin RNA against PTEN enhances regenerative growth of corticospinal tract axons after spinal cord injury. J Neurosci 33(39):15350-15361. https://doi.org/10.1523/JNEUROSCI.251013.2013

34. Guo X, Snider WD, Chen B (2016) GSK3beta regulates AKTinduced central nervous system axon regeneration via an eIF2Bepsilon-dependent, mTORC1-independent pathway. Elife 5: e11903. https://doi.org/10.7554/eLife.11903

35. Belin S, Nawabi H, Wang C, Tang S, Latremoliere A, Warren P, Schorle H, Uncu C et al (2015) Injury-induced decline of intrinsic regenerative ability revealed by quantitative proteomics. Neuron 86(4):1000-1014. https://doi.org/10.1016/j.neuron.2015.03.060

36. Christie KJ, Webber CA, Martinez JA, Singh B, Zochodne DW (2010) PTEN inhibition to facilitate intrinsic regenerative outgrowth of adult peripheral axons. J Neurosci 30(27):9306-9315. https://doi.org/10.1523/JNEUROSCI.6271-09.2010

37. Saijilafu Hur EM, Liu CM, Jiao Z, Xu WL, Zhou FQ (2013) PI3KGSK3 signalling regulates mammalian axon regeneration by inducing the expression of Smad1. Nat Commun 4:2690. https://doi.org/ $10.1038 /$ ncomms 3690

38. Huang Z, Hu Z, Xie P, Liu Q (2017) Tyrosine-mutated AAV2mediated shRNA silencing of PTEN promotes axon regeneration of adult optic nerve. PLoS One 12(3):e0174096. https://doi.org/10. 1371/journal.pone.0174096

39. Derynck R, Zhang YE (2003) Smad-dependent and Smadindependent pathways in TGF-beta family signalling. Nature 425(6958):577-584. https://doi.org/10.1038/nature02006

40. Moustakas A, Heldin CH (2009) The regulation of TGFbeta signal transduction. Development 136(22):3699-3714. https://doi.org/10. 1242/dev.030338

41. Foletta VC, Lim MA, Soosairajah J, Kelly AP, Stanley EG, Shannon M, He W, Das S et al (2003) Direct signaling by the BMP type II receptor via the cytoskeletal regulator LIMK1. J Cell Biol 162(6):1089-1098. https://doi.org/10.1083/jcb.200212060
42. Hocking JC, Hehr CL, Bertolesi G, Funakoshi H, Nakamura T, McFarlane S (2009) LIMK1 acts downstream of BMP signaling in developing retinal ganglion cell axons but not dendrites. Dev Biol 330(2):273-285. https://doi.org/10.1016/j.ydbio.2009.03.027

43. Lee-Hoeflich ST, Zhao X, Mehra A, Attisano L (2005) The Drosophila type II receptor, wishful thinking, binds BMP and myoglianin to activate multiple TGFbeta family signaling pathways. FEBS Lett 579(21):4615-4621. https://doi.org/10.1016/j. febslet.2005.06.088

44. Wen Z, Han L, Bamburg JR, Shim S, Ming GL, Zheng JQ (2007) BMP gradients steer nerve growth cones by a balancing act of LIM kinase and slingshot phosphatase on ADF/cofilin. J Cell Biol 178(1):107-119. https://doi.org/10.1083/jcb.200703055

45. Groppe J, Greenwald J, Wiater E, Rodriguez-Leon J, Economides AN, Kwiatkowski W, Baban K, Affolter M et al (2003) Structural basis of BMP signaling inhibition by noggin, a novel twelvemembered cystine knot protein. J Bone Joint Surg Am 85A(Suppl 3):52-58

46. Sahni V, Mukhopadhyay A, Tysseling V, Hebert A, Birch D, McGuire TL, Stupp SI, Kessler JA (2010) BMPR1a and BMPR1b signaling exert opposing effects on gliosis after spinal cord injury. J Neurosci 30(5):1839-1855. https://doi.org/10.1523/ JNEUROSCI.4459-09.2010

47. Matsuura I, Taniguchi J, Hata K, Saeki N, Yamashita T (2008) BMP inhibition enhances axonal growth and functional recovery after spinal cord injury. J Neurochem 105(4):1471-1479. https:// doi.org/10.1111/j.1471-4159.2008.05251.x

48. Coombs JS, Curtis DR, Landgren S (1956) Spinal cord potentials generated by impulses in muscle and cutaneous afferent fibres. J Neurophysiol 19(5):452-467. https://doi.org/10.1152/jn.1956.19.5. 452

49. Byrnes KR, Fricke ST, Faden AI (2010) Neuropathological differences between rats and mice after spinal cord injury. J Magn Reson Imaging 32(4):836-846. https://doi.org/10.1002/jmri.22323

50. Tang X, Davies JE, Davies SJ (2003) Changes in distribution, cell associations, and protein expression levels of NG2, neurocan, phosphacan, brevican, versican V2, and tenascin-C during acute to chronic maturation of spinal cord scar tissue. J Neurosci Res 71(3):427-444. https://doi.org/10.1002/jnr.10523

51. Potter K, Saifuddin A (2003) Pictorial review: MRI of chronic spinal cord injury. Br J Radiol 76(905):347-352. https://doi.org/ $10.1259 / \mathrm{bjr} / 11881183$

Publisher's Note Springer Nature remains neutral with regard to jurisdictional claims in published maps and institutional affiliations. 